
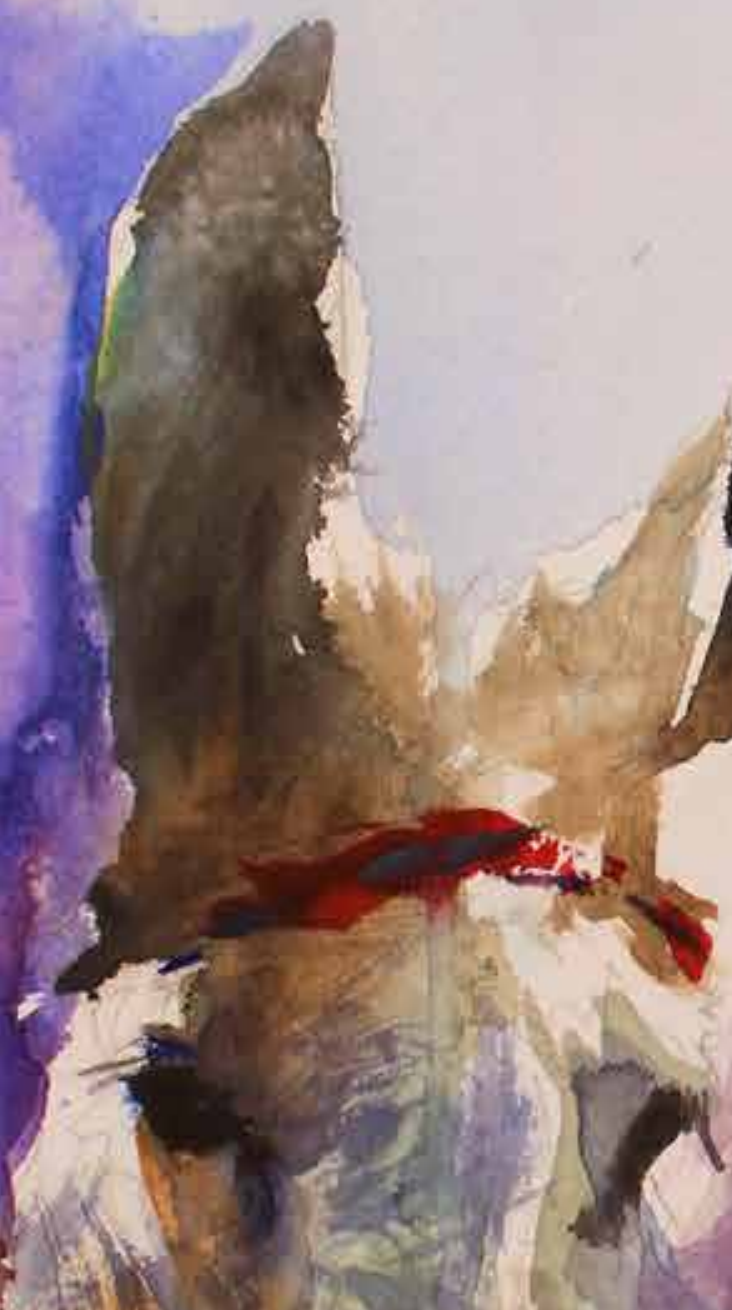
2. Whe?
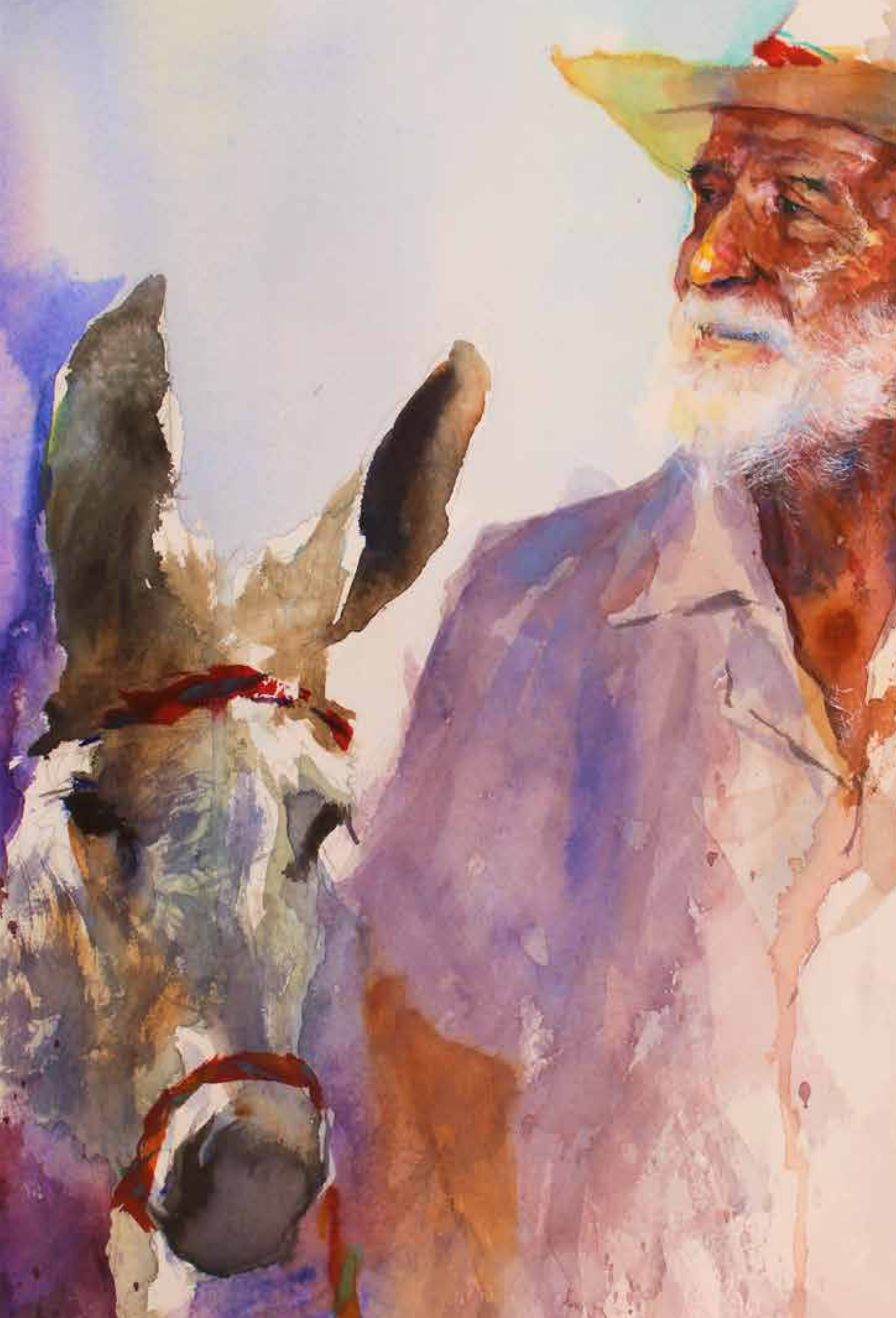

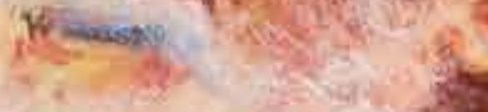

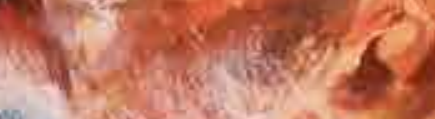

${ }_{4}^{20}$
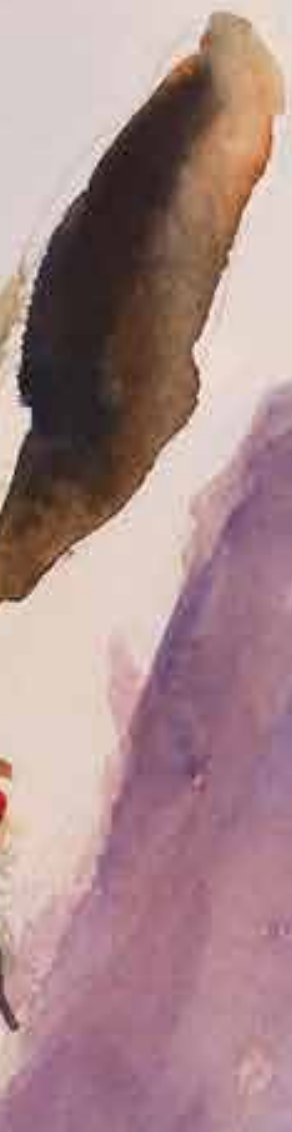


\section{Prisión verde (fragmento)}

El zancudo, la malaria, la disentería, la gripe, la neumonía, estiraban sus brazos fatales, estrujando a los campeños. iDías terribles para las peonadas y sus familias sintiendo los mordiscos saurinos del hambre, la miseria y la muerte!

$Y$, sin embargo, esos hombres no protestaban $n i$ suplicaban piedad. Seguían la fuerza de sus destinos sin presentarle resistencia, sin lanzar una queja, puesto que de sobra sabian que, para ellos, esclavos de la sociedad, estaban probibidas las iluminaciones de la justicia y habian olvidado cuerdamente la bipotética esperanza de un Dios, porque éste, espantado de la existencia de los bumildes, prefería mejor la grata compañia de los jefes con las pupilas alucinadas de fasto y holgura. Los ataques que lanzaban contra Dios eran tan formidables como: los que dirigían a los jefes gringos. Las mujeres no protestaban por esas blasfemias: aparentaban no escucharlas y muchas se solidarizaban con ellas.

Cada día aumentaban los enfermos y la muerte, presurosa, no les daba ni tiempo para llegar basta el Dispensario de Coyoles Central y menos al hospital del puerto. Las fiebres palúdicas no detenían a los trabajadores que lograban chance, aun bajo la inclemencia de las lluvias; laboraban basta caer moribundos, con los dardos de las neumonías, de la fiebre de aguas negras, de las pulmonías fatales.

\section{Ramón Amaya Amador}

\section{Ulises Rivera}




\title{
2. Inmigración y colonización en Honduras durante la Reforma Liberal, 1876-1891
}

\author{
Patricia Elizabeth Castillo Canelas' \\ DOI: https://doi.org/10.5377/pdac.v15i0.8114 \\ Recibido: 25/02/2019 - Aceptado:07/05/2019
}

\begin{abstract}
Resumen: El presente artículo tiene como objetivo dar a conocer como en su intento por desarrollar al país, diferentes gobiernos, especialmente durante el período comprendido entre 1876 y 1891, lo entregaron al capital extranjero. Las concesiones y contratas fueron el medio práctico más conveniente para intentar insertar al país en la economía mundial. Como resultado de las diferentes políticas migratorias y de colonización desarrolladas por el gobierno hondureño durante el período conocido como Reforma Liberal, en su afán de buscar, alentar y favorecer al capital extranjero, el gobierno quedó sometido a su voluntad. Y que a pesar de esa política concesionaria ofrecida a aquellos "agentes promotores" para poblar el basto y despoblado territorio hondureño, los resultados fueron escasos, casi nulos. Metodológicamente se hizo un análisis a las fuentes primarias consultadas como ser las gacetas del gobierno y las memorias de la Secretaría de Estado en los Despachos de Gobernación, Justicia y Fomento, así como una revisión bibliográfica (en publicaciones extranjeras y nacionales), este proceso permitió identificar cómo, los recursos nacionales fueron ofrecidos al mejor postor.
\end{abstract}

Palabras clave: política migratoria, concesiones, colonización

\section{Immigration and colonization in Honduras during the Liberal Reform, 1876-1891}

\begin{abstract}
The purpose of this article is to make known how in its attempt to develop the country, specifically during 1876 and 1891, different governments hand it to foreign capital. The concessions and contracts were the most convenient practical means to try to insert the country into the world economy. As a result of the different migration and colonization policies developed by the Honduran government during the period known as the Liberal Reform, in its eagerness to seek, encourage and favor foreign capital, the government was subject to its will. Despite this concessionary policy offered to those "promoters" to populate the vast and depopulated Honduran territory, the results were scarce, almost nil. The analysis of the primary sources consulted, such as the government gazettes and the reports of the Secretary of State in the Offices of the Interior, Justice and Development, as well as a bibliographical revision (in foreign and national publications), allowed to present how, the national resources were offered to the highest bidder.
\end{abstract}

Keywords: migration policy, concessions, colonization

\section{Introducción}

Posterior a la independencia, el desarrollo económico de Honduras ha estado ligado a la explotación y exportación de productos primarios (ganadería, agricultura y minería) con escasos beneficios. Entre los problemas que los primeros gobiernos debieron enfrentar estaba la escasa población, la carencia de vías que comunicaran el extenso territorio, la falta de conocimiento técnico y de recursos financieros. Sin embargo, los intelectuales del momento conocían de la riqueza de los recursos naturales del país y del poco conocimiento de estos en el exterior.

El artículo que se presenta a continuación tiene como objetivo dar a conocer cómo en su intento por desarrollar al país, diferentes gobiernos durante el contexto de la Reforma Liberal lo entregaron al capital extranjero. Se buscaba atraer población y recursos extranjeros mediante la concesión de los recursos naturales y brindar beneficios a todo extranjero deseoso de trabajar y obtener una propiedad agrícola, minera o industrial para establecerse en el país. Las concesiones y contratas fueron el medio práctico más conveniente para intentar insertar al país en la economía mundial.

Como resultado de las diferentes políticas migratorias y de colonización desarrolladas por el gobierno hondureño durante el período conocido como Reforma Liberal, en su afán de buscar, alentar y favorecer al capital extranjero, el gobierno quedó sometido a su voluntad. Y que a pesar de esa política concesionaria ofrecida a aquellos "agentes promotores" para poblar el basto y despoblado territorio hondureño, los resultados fueron escasos, casi nulos. Las fuentes hemerográficas primarias consultadas fueron las gacetas del gobierno y las memorias de la Secretaría

1 Master en Metodologías de Investigación Económica y Social, Licenciada en Historia, Coordinadora del Fondo Documental Histórico (DEGT). e-mail: patricia.castillo@unah.edu.hn 
de Estado en los Despachos de Gobernación, Justicia y Fomento. Así como una revisión bibliográfica de textos (en publicaciones extranjeras y nacionales).

José Cecilio del Valle (1777-1834) expuso ante el gobierno federal, la necesidad de crear una ley de inmigración y dar a conocer las riquezas del país para atraer extranjeros útiles para la agricultura, y brindarles toda la protección necesaria para su establecimiento, auxiliándoles en los costos de viaje y primeros cultivos (Amaya, 2000, pág. 25).

Para José María Medina (1826-1878) la población era la base del progreso, durante su gobierno se decretó la Ley de Inmigración el 26 de febrero de 1866 aprobada por el Congreso Nacional, en ella se ofrecía a todos los extranjeros deseosos de domiciliarse en Honduras, los mismos derechos de los nativos, también se les facultaba, en caso de tener éxito en los terrenos trabajados, a beneficiarse de los recursos de los lotes contiguos a sus fincas, a no prestar servicio militar por un período de diez años, ni a pagar en concepto de introducción de insumos las tasas municipales y fiscales.

Marco Aurelio Soto Martínez (1846-1908) también expuso ante el Congreso Nacional la necesidad de hacer venir población honrada e industriosa y así mejorar las condiciones territoriales del país, pues este era un extenso, desolado e incomunicado territorio (Soto, 1879, pág. 14-18). Había escases de mano de obra y ningún conocimiento especializado para desarrollar la tierra o la industria. No fueron pocos los extranjeros que se interesaron en la política inmigratoria y concesionaria que ofrecía el país, pero no todas las familias extranjeras que llegaron estuvieron dispuestas a quedarse en el territorio, pues la geografía, el clima y el costo representaron un verdadero reto que no todos estaban dispuestos a enfrentar.

Luis Bográn Barahona (1849-1895) asume la presidencia en noviembre de 1883 tras la renuncia de Soto. Bográn continua con el proceso de transformación del país, y la política concesionaria del gobierno antecesor.

\section{Metodología}

La información utilizada para elaborar este estudio, se obtuvo de diversas fuentes hemerográficas como las gacetas del gobierno correspondientes a los años 1879 (\#42 y \#50), 1881 (\#118), 1882 (\#163, \#167, \#170) 1883 (\#207, \#209, \#210, \#210, \#220, \#222, \#227, \#227, \#229) 1888 (\#395) 1889 (\#477) y 1891 (\#749, \#750); y las memorias presentadas por la Secretaría de Estado en los Despachos de Gobernación, Justicia y Fomento al Congreso Nacional en 1883, donde se publicaron no solo las concesiones y contratas sino también una serie de beneficios que obtendría aquellos extranjeros dispuestos a radicarse en el país.

Con las fuentes secundarias, nacionales y extranjeras se amplió la información, y entre ambas fue posible:

- Identificar a los beneficiarios directos e indirectos de las concesiones y contratas otorgadas por el gobierno.

- Identificar los diferentes tipos de actividades industriales, comerciales y de servicios que fueron dados en concesión. Su ubicación y capacidad de producción.

- Comprender el papel que jugó el Estado en el desarrollo y diversificación de las actividades productivas y la participación de los miembros del gobierno en los proyectos estatales.

\section{Discusión de resultados}

\subsection{Un país desconocido}

Fuera de las fronteras, nadie conocía las bondades del territorio hondureño. El esfuerzo común de varios gobiernos era dar a conocer dichas riquezas a través de publicaciones y atraer extranjeros con capacidades para desarrollar el país. Muchos fueron los extranjeros que se aventuraron a recorrer todos los rincones enfrentando y superando las dificultades que encontraban a su paso.

Durante su estadía, que en algunos casos fue por varios meses e incluso años, registraron en sus cuadernos de viaje todo lo observado durante su travesía, cuestiones sobre la flora y fauna, montañas, ríos y valles, clima, costumbres y personajes. Así fue entonces que surgieron varias publicaciones sobre la región en general y el país en especial. En el Cuadro $\mathrm{N}^{\circ} 1$, se presenta un breve ejemplo de ellas.

En términos generales, todas las publicaciones exponían las riquezas de Honduras, de su extenso, pero escasamente poblado territorio, del buen clima y de las grandes extensiones de tierra fértiles pero que hasta ese momento eran inútiles y de las cuales se podría obtener gran ventaja si se hiciera un esfuerzo para aumentar la población invitando y fomentando la inmigración. Se indicaba que los puertos por donde se podía llegar eran Puerto Cortés, Omoa y Trujillo, en la costa Norte y Amapala en la región sur y más cercana a la capital. La agricultura, repetían una y otra vez, es la verdadera base de la riqueza nacional, y cuando se cultiven sus espléndidos campos hasta una cuarta parte de la totalidad de sus recursos, Honduras tendrá un futuro brillante (Charles, 1890, pág. 91). 
Cuadro $\mathbb{N}^{\circ} 1$ Publicaciones sobre las concesiones en Honduras

\begin{tabular}{|c|c|c|}
\hline Lugar de publicación y año & Autor & Título \\
\hline Edimburgo, 1822 & Thomas Strangeways & $\begin{array}{l}\text { Sketch of the Mosquito shore, including the } \\
\text { territory of poyais, descriptive of the country }\end{array}$ \\
\hline Londres, 1842 & John L. Stephen & $\begin{array}{l}\text { Incidents of travel in Central American, Chi- } \\
\text { apas and Yucatan. vol. I }\end{array}$ \\
\hline Londres, 1850 & John Baily & $\begin{array}{l}\text { Central America; describing each of the } \\
\text { states of Guatemala, Honduras, Salvador, } \\
\text { Nicaragua, and Costa Rica; their natural fea- } \\
\text { tures, products, population, and remarkable } \\
\text { capacity for colonization. With three views. } \\
\text { (many years resident in the country) }\end{array}$ \\
\hline \multirow{2}{*}{ Nueva York, 1851} & Marmaduke B. Sampson & $\begin{array}{l}\text { Central American and the transit between } \\
\text { the oceans }\end{array}$ \\
\hline & $\begin{array}{c}\text { The american whig review (new } \\
\text { series, vol. II, whole vol. XIII) }\end{array}$ & Central American and the administration \\
\hline Londres, 1853 & J. Froëbel & $\begin{array}{c}\text { Seven years travel in Central America, north- } \\
\text { ern Mexico and the far west of the United } \\
\text { States }\end{array}$ \\
\hline Nueva York, 1854 & Ephran George Squier & Honduras and Guatemala \\
\hline Nueva York, 1856 & $\begin{array}{c}\text { Harper's New Monthly Magazine } \\
\text { (volumen XII \#LXXII de mayo de } \\
1856 \text { ) }\end{array}$ & A visit to the silver mines of Central America \\
\hline Nueva York, 1857 & William Wells & $\begin{array}{l}\text { Explorations and adventures in Honduras, } \\
\text { comprising sketches of travel in the gold } \\
\text { region of Olancho and a review of the history } \\
\text { and general resources of America Central } \\
\text { (with original maps, and numerous ilustra- } \\
\text { tions) }\end{array}$ \\
\hline Londres, 1868 & $\begin{array}{c}\text { Real Sociedad de Geografía, } \\
\text { volumen XII Nos. I-V }\end{array}$ & Explorations in Central America \\
\hline Chicago, 1888 & The American Honduras Co. & $\begin{array}{l}\text { Honduras and the Perry Land Grant: a new } \\
\text { field for the farmer, stockman, lumberman } \\
\text { and laborer }\end{array}$ \\
\hline Chicago, 1890 & Cecil Charles & $\begin{array}{l}\text { Honduras: the land of great depths, with } \\
\text { maps and portraits. }\end{array}$ \\
\hline Tegucigalpa, 1897 & Manuel Lemus y H.G. Bourgeois ${ }^{2}$ & $\begin{array}{l}\text { Breve noticia sobre Honduras. Datos geográ- } \\
\text { ficos, estadísticos e informaciones prácticas }\end{array}$ \\
\hline
\end{tabular}

Fuente: Elaboración propia con diferentes fuentes.

2 Miembros de la comisión científica del gobierno de la República de Francia en Centro América presentaron un informe en el que daban datos útiles sobre la abundancia y variedad de los ricos elementos que posee el país y que encarnan un porvenir de gran prosperidad datos útiles sobre la abundancia y variedad de los ricos elementos que posee el país y que encarnan un porvenir de gran prosperidad. 


\subsection{Política concesionaria y contratas (no mineras ni bananeras) otorgadas por el gobierno}

Cuando en 1876 se hacen cargo de la administración del país Marco Aurelio Soto y Ramón Rosa, bajo la consigna de paz y progreso de la Reforma Liberal, se asentaron las bases jurídico-administrativas necesarias para superar la difícil situación en que encontraron al país. De esa manera Honduras entraba en una era de cambios y reformas, de transformación, legitimización y consolidación del aparato estatal.

La Reforma Liberal fue un movimiento ideado para eliminar todo vestigio colonial en las instituciones establecidas por España en América. Las nuevas y reformistas leyes declararon libertad de cultos, eliminaron el diezmo y secularizaron los cementerios, surgieron nuevas instituciones administrativas, educativas y culturales. Se reguló y favoreció la minería y la agricultura, ofreciendo beneficios a los agricultores nacionales y extranjeros.

La apertura de carreteras permitiría la comunicación interna del amplio y despoblado territorio, se instalaron las primeras líneas telegráficas, y se reguló la administración portuaria para mejorar las recaudaciones fiscales e incrementar el comercio. Hubo confiscación de tierras realengas, eclesiásticas y comunales baldías para desarrollar la agricultura en manos particulares, aunque este proceso había iniciado con anterioridad según los decretos de 1829,1837 y 1843 , fue durante esta administración que se incrementó dicha actividad (Argueta, 1982, pág. 13).

El 29 de abril de 1877, en la ciudad de La Paz, Marco Aurelio Soto aprobó el decreto para el fomento de la agricultura, favoreciendo los cultivos de café, caña de azúcar, jiquilite o de cacao; ordenó a los gobernadores políticos la inscripción de los agricultores para que recibieran las garantías y ventajas que la ley ofrecía tanto a los nacionales como a los extranjeros (Rosa, 1954, págs. 68-71). También mediante acuerdo gubernativo la Secretaría de Estado en el Despacho de Fomento, en noviembre de 1882, protegió la industria minera brindándoles igualmente los beneficios de introducción libre de impuestos y uso de los recursos naturales (Vallejo, 1891, pág. 520).

Las diversas publicaciones que daban a conocer al país incluían en sus páginas algunas leyes, y como es el caso del boletín \#57 del Bureau of the American Republic, incluyó la Constitución decretada el 2 mayo de 1880. En el artículo \#25 capítulo IV sobre "Garantías de Orden y Progreso" explica que:
El Estado proporcionará en todo sentido el bienestar y el avance del país, promoviendo el progreso de la agricultura, la industria y el comercio, la inmigración, la colonización de terrenos baldíos y la construcción de carreteras y ferrocarriles, el establecimiento de nuevas industrias y la fundación del instituto de crédito, la importación de capital extranjero y la exploración y canalización de ríos y lagos, mediante la protección de estos objetos y concesiones temporales de privilegios y recompensas estimulantes (1892, pág. 71).

$\mathrm{Y}$ todas las solicitudes de concesiones presentadas a las diferentes secretarías del gobierno fueron aprobadas. Los beneficiarios, nacionales y extranjeros, fueron muchos y los rubros dados en concesión incluían todos los aspectos económicos, agrícolas, mineros, industriales y financieros.

En todas esas empresas el gobierno puso sus esperanzas para obtener grandes beneficios, pero ¿cómo lo lograrían si a todos se les eximió del pago de impuestos fiscales y municipales por la introducción de los insumos necesarios para establecer y desarrollar dichos negocios? Además, todos pudieron aprovecharse indiscriminadamente de los recursos naturales que estaban dentro del circuito concesionado. ¿quién los controlaba, con qué mecanismo? Las grandes empresas traían a sus empleados del exterior, y estas no reportaban fielmente sus ganancias al gobierno. La única condición del gobierno era que, si en el término de un año no se habían iniciado operaciones, las tierras volverían a sus dueños originales: las municipalidades y el Estado.

A continuación, una breve reseña de algunas concesiones dadas durante la administración presidencial de Marco Aurelio Soto y Luís Bográn:

a. En 1882 se firmó una contrata con los señores Jorge W. Shears y G. Reinhold Fritzgaertner para canalizar los ríos Blanco y Ulúa y establecer en ellos una navegación regular por medio de buques de vapor, lo mismo que traer inmigrantes para formar centros de población para desarrollar el comercio de la República en la zona comprendida entre los ríos mencionados (La Gaceta \#167, 1882). Fritzgaertner (1849-Honduras 1916), de origen prusiano, era inspector general de minas y geólogo del gobierno (La Gaceta \#212, 1883), también editó en inglés el bisemanario Honduras Progress, publicación que brindaba datos sobre Honduras.

b. Entre 1882 y 1883 mediante decreto legislativo \#8 se firmó contrato con Joseph L. Hance y John J. Waterbury, de Nueva York, para la construcción de un 
ferrocarril interoceánico desde Puerto Cortés a cualquier punto de la Bahía de Fonseca en la costa del Pacífico. Y con el decreto \#9 se les autorizó la fundación del Banco Agrícola Hipotecario con oficinas en Tegucigalpa y sucursales en Amapala, Puerto Cortés y Trujillo. El objetivo del banco era conceder préstamos a los agricultores bajo buenas garantías hipotecarias y buenos plazos a un interés del 10\% anual (La Gaceta \# 207 y \# 209, 1883).

c. De igual manera se concesionó a E. A. Lever (cónsul de Honduras en Nueva Orleans y representante de los señores Robertson y Lacey de la misma ciudad), la canalización y navegación del río Chamelecón, establecer el cultivo de algodón en el valle de San Pedro y una fábrica manufacturera de telas, además se comprometieron traer familias de colonos para trabajar en sus empresas (La Gaceta \#220, 1883). Y mediante decreto \#13 de 1889 se les autoriza por el término de 10 años, la canalización de los ríos Ulúa hasta Santa Bárbara, el Blanco hasta el sitio llamado La Imprenta y el Comayagua hasta el punto por donde pasa el ferrocarril (La Gaceta \#477, 1889).

d. La Secretaría de Estado en el Despacho de Fomento acordó otorgar a Tomás Russel Lombard una concesión durante 15 años, para el cultivo a gran escala de plantas fibrosas ${ }^{3}$ en la jurisdicción de Tela, aprovechar libremente los recursos nacionales, introducción libre de impuestos de maquinaria, instrumentos agrícolas, madera para la construcción de embarcaciones a vapor o vela para uso exclusivo de la empresa (La Gaceta, \#227, 1883). Lombard fue presidente de las compañías mineras Central American Sindycate Co. y vicepresidente de la Yuscarán Mining Co.

e. Según acuerdo del 26 de abril de 1883 , se concedió a Juan J. Fernández el privilegio exclusivo por 10 años, para establecer una fábrica de papel, la que debía surtir los departamentos de Tegucigalpa, Olancho, El Paraíso y Choluteca (La Gaceta \#229, 1883).

f. Juan Federico Debrot ${ }^{4}$, Máximo Gómez Báez y José Antonio Maceo obtuvieron en 1883 una concesión para el establecimiento de una colonia agrícola compuesta de nacionales y extranjeros (principalmente cubanos) a inmediaciones del lugar llamado "Choloma" en el departamento de Santa Bárbara, teniendo como propósito principal el cultivo y elaboración del tabaco (La Gaceta \#210, 1883).

g. Washington S. Valentine obtuvo concesión por 20 años para el establecimiento en toda la República, de beneficios para el descubrimiento y explotación de agua salina, piedra de sal, petróleo, gas natural y agua dulce. En los terrenos donde se descubrieran esos minerales, podría establecer talleres y casas de habitación para los empleados (La Gaceta \#681, 1890).

h. La Compañía Francesa Agrícola de Honduras recibió en 1891 varias concesiones para establecer empresas agrícolas y obras industriales entre los municipios de La Ceiba y Balfate, en el departamento de Colón, además se le cedieron 10 caballerías de terreno. Entre las fábricas a instalar estaban una de ladrillos y baldosas barnizada, de conservas, dulces y jaleas, de alcohol y sus derivados extraído del plátano (La Gaceta \#749-750, 1891).

i. The American-Honduras Co. compañía organizada en Chicago, Illinois-USA (1888, pág. 5), exponía en su propaganda que ...

Con el propósito de fomentar la inmigración, y mediante el desarrollo de los grandes recursos naturales de Honduras, el gobierno de esa república ha concedido a la compañía lotes de tierra alternos... comenzando en un punto en el medio de la parte más profunda del canal que conecta la laguna de Caratasca con el mar Caribe y extendiéndose desde allí en dirección noroeste y oeste a lo largo de la costa de dicho mar hasta los 85 grados de longitud en el oeste de Greenwich...Por lo que se han preparado los documentos de venta de tierras a aquellos individuos o grupos de colonos que deseen establecerse a lo largo de la costa norte.

El gobierno de Bográn firmó con los representantes de la compañía E.W. Perry, Frank M. Imboden, antiguo propietario de la mina Opoteca, un acuerdo con el objetivo de poblar la vasta pero poco conocida región oriental de la república, que se llama Mosquito (Mosquitia), la compañía tenía sus oficinas en Tegucigalpa, Patuca, Juticalpa y Catacamas (Charles ob. cit, 92).

3 Son aquellas plantas cuyas raíces permanecen cerca de la superficie del suelo y reúnen nutrientes antes de que la humedad y los minerales se hundan más profundamente en él. Este tipo de plantas se utilizan generalmente para evitar la erosión. 4 Cónsul de su Majestad británica en los puertos de Omoa y Puerto Caballos o Cortés (La Gaceta \#118, 1881) 
j. En mensaje enviado por el cónsul de Estados Unidos en Honduras, Alfred K. Moe informó que el capital requerido para que una familia pudiera establecerse y cultivar un área de 100 manzanas ascendía a $\$ 1,131.00$ ... La tierra se puede obtener sin mayor costo de acuerdo al uso, previo al pago de un impuesto anual al gobierno de 25 centavos por hectárea... (Moe, 1904:58)

Otros extranjeros que también se beneficiaron de la apertura de los gobiernos Soto/Bográn fueron algunos militares exiliados procedentes de Cuba que, luego de la firma del Pacto del Zanjón buscaron amparo en el país, entre ellos sobresale el polaco Carlos Roloff Mialofsky (Karol Rolow Mialowski, 1842-1907), que de Estados Unidos se trasladó a la isla donde trabajó en los campos azucareros y participó en la guerra de los diez años. Fue nombrado por el gobierno norteamericano como vicecónsul con residencia en Amapala (La Gaceta \#227, 1883). También se benefició de la política concesionaria del gobierno cuando el 27 agosto de 1887 se le permitió destilar aguardiente de plátano (La Gaceta \#395, 1888). Casado con Galatea Guardiola Arbizú (1857-1910), hija del Presidente Santos Guardiola (1816-1862), Roloff llegó a Puerto Cortés en 1881 con el doctor Eusebio Hernández Pérez (1853-1933), a quién se le debe la organización del Hospital General hoy Hospital San Felipe, posteriormente nombrado catedrático en la Universidad Central de Honduras.

Ese mismo año llego procedente de Estados Unidos Francisco Adolfo (Flor) Crombet Tejera (1851-1895) que había escapado de las cárceles españolas. El gobierno lo nombró Juez Suplente del Tribunal Supremo de Guerra, Comandante de Armas del departamento de La Paz, hasta 1884 (Gacetas \#222, 1883 y \#287, 1884 respectivamente). Por razones distintas llegó al puerto de Trujillo, Francisco de Paula y Flores (1844-1891), allí se reunió con otro cubano, Manuel Fleury que había llegado años antes al país. Ambos dirigieron una institución de enseñanza en el puerto, posteriormente Francisco partió hacia Olancho donde se le ofreció la dirección de una escuela de primeras letras pronta a fundarse en Juticalpa. Allí fundó y mantuvo con su propio esfuerzo la Escuela Primaria Superior (Cruz, 1939, pág. 33).

José Antonio de la Caridad Maceo y Grajales (1845-1896) llegó a Honduras con su hermano Marcos en julio de 1881. Durante su estadía en Tegucigalpa se reunió con Estrada Palma y José Joaquín Palma. Del gobierno obtuvo el grado de General de División, en 1882 se le nombró Juez Suplente del Tribunal Supremo de Guerra (La Gaceta \#163,
1882) y Comandante de los puertos de Omoa y Puerto Cortés (La Gaceta \#170, 1882). También fue Jefe de las Plazas de Tegucigalpa, Comayagua y La Paz. Cuando fue a tomar posesión de Puerto Cortés y Omoa, pasó por San Pedro Sula donde se reunió con la familia cubana Gómez Toro (Franco, 1954-1955, págs. 232-252).

El poeta y maestro José Joaquín Palma y Lasso de la Vega (1844-1911), llegó a Honduras y se le nombró secretario privado del Presidente Soto, fue catedrático de Arte Métrica y Declamación en la Escuela Nacional de Bellas Artes. En 1883 en sociedad con G. Frankel obtuvieron del gobierno una concesión para la fabricación de sacos de tela para enfardar café, añil, cacao, azúcar y otros con libre introducción de insumos para la elaboración de los mismos (La Gaceta, \#210, 1883). Máximo Gómez Báez (1836-1905) llegó en 1879, invitado por el gobierno Soto-Rosa por su experiencia militar para la formación profesional del ejército, pues era necesario contar con un ejército respetable, instruido y disciplinado (Rosa, 1954; 171 y 183). Se le nombró General de División (La Gaceta \#42, 1879), y posteriormente encargado de la comandancia de Amapala con amplias facultades, para que dicte las medidas que juzgue convenientes con respecto a la organización militar y seguridad (sic) del puerto de Amapala (la Gaceta \#50, 1879). José Dolores Pérez Gómez (1861-1931), llegó con su tío el General Máximo Gómez Báez en marzo de 1880 al Puerto de Amapala (La Gaceta \#67, 1880: 3). José Dolores se estableció en San Pedro Sula y contrajo matrimonio con Paulina Follin Bardales (1864-1936), hija del Cónsul de Estados Unidos en Omoa, Charles Follin y María Tomasa Bardales. Cofundador y directivo de la Logia Masónica Eureka \#2 (1915) de San Pedro Sula y del Casino Sampedrano fundado en 1912 (Bonilla, 2001). Propietario del Teatro Variedades de aquella localidad (Rev. Honduras, 1929, págs. 7-8).

Tomás Cirilo José de la Caridad Estrada y Palma (18351908) nombrado Director General de Correos y Telégrafos, trabajó como profesor de Pedagogía, Física y Química en el Colegio Nacional de $2^{2}$ enseñanza de Tegucigalpa, institución que más tarde sería su director (La Gaceta \#218, 1883), Secretario de la Junta Directiva del Hospital General (1882). Casado con otra de las hijas del Presidente Guardiola, María Genoveva de Jesús Guardiola Arbizú (1858-1926). Estrada Palma alcanzó la presidencia de Cuba (1876-1877/1902-1906).

En términos generales, cada una de las concesiones tenía un apartado en el que se especificaba que, si en el tér- 
mino de uno o dos años la propiedad cedida no era utilizada, esta debía volver a su propietario original o sea al Estado, pero ¿qué porcentaje de las tierras cedidas y no utilizadas éste recuperó, si es que las recuperó? Además, al haber analizado los términos en que se dieron cada una de las contratas y concesiones, nos preguntamos ¿en qué y porqué fallaron estas políticas? Una de las causas probables sería falta de experiencia de los administradores gubernamentales, y la no existencia de un grupo nacional social y económicamente fuerte con un sentimiento nacional suficientemente desarrollado que se hiciera cargo del proyecto de desarrollo, todos se acomodaron y subordinaron al capital extranjero y su forma de operar. Entonces, también hay que considerar si este fue el inicio del capital originario de algunas familias.

\section{Conclusiones}

Los procesos migratorios han estado presentes en todos los aspectos del desarrollo social y se han producido por diversos motivos. Los grupos migratorios llevan consigo su cultura, costumbres y esperanzas de alcanzar un mejor destino. De África pasaron a Europa y de allí a América y en cada una de esas regiones fueron formando distintas comunidades. Muchos años debían pasar y muchos acontecimientos hasta llegar a la Honduras de mediados de Siglo XIX. Donde se desarrolla este corto e interesante estudio, sobre algunas de las políticas migratorias y de colonización creadas para desarrollar el país.

El desconocimiento de aquella región llamada Honduras, se fue disminuyendo a medida que fueron surgiendo publicaciones que exponían las riquezas del país y las bondades de las políticas gubernamentales que permitían asentarse, apropiarse y explotar bajo cualquier rubro la tierra o establecer variedad de industrias. Las concesiones y contratas autorizadas por el gobierno favorecieron tanto a norteamericanos como a europeos $y$ algunos latinoamericanos, quienes con capital (algunos) y conocimientos establecieron sus negocios. ¿Pero dónde quedaron las ganancias obtenidas por ellos? Sino es que, en los bancos extranjeros, pero no en Honduras.

El gobierno les facilitó todo, aún a costa de no percibir los impuestos fiscales y municipales tan necesarios para sostenerse. De allí que éste siempre estuviera carente de fondos y sometido a la voluntad de dichos empresarios. ¿Dónde y en que manos quedó el país que ofrecía sus recursos para desarrollarse y porqué no logró el tan deseado crecimiento? Honduras sigue siendo un país con muchos recursos, pero los intereses sectarios-particulares son demasiados. Quienes llegaron y contribuyeron con el fortalecimiento de la institucionalidad nacional no tenían la intención de establecerse definitivamente. Honduras fue para ellos un lugar donde pasar una tempestad hasta que las cosas mejoraran en sus regiones de origen.

\section{Referencias bibliográficas}

- Acuerdo en que se hacen varias concesiones a don Tomás R. Lombard para el cultivo de plantas fibrosas en el departamento de Yoro. La Gaceta \#227, 14 agosto 1883, serie 23

- Acuerdo en que se hacen varias concesiones a Juan J. Fernández para el establecimiento de una fábrica de papel. $L a$ Gaceta \#229, 28 agosto 1883, serie 23

- Acuerdo de nombramiento del General Máximo Gómez Comandante del Puerto de Amapala. La Gaceta \#50, 23 julio $1879,5^{a}$ serie

- Acuerdo en que se confiere el despacho de General de División de Honduras al General Máximo Gómez. La Gaceta de Honduras \#42, 22 abril 1879, 4a serie

- Acuerdo en que se nombra al General don José Antonio Maceo Comandante de los puertos de Puerto Cortes y Omoa. La Gaceta \#170, 31 julio 1882, serie 17

- Acuerdo en que se nombra al General Flor Crombet, Juez Suplente del Tribunal Supremo de Guerra. La Gaceta \#222, 10 julio 1883 , serie 23 , año VII

- Acuerdo en que se otorgan varios privilegios a Mr. Washington S. Valentine, para establecer una empresa para la fabricación y explotación de sal, petróleo, etc. La Gaceta \#681, 7 agosto 1890, serie 69

- Acuerdo en que se permite a don Carlos Roloff destilar aguardiente de plátanos. La Gaceta \#395, 31 enero 1888, serie 40

- Acuerdo que otorga a la "Compañía Francesa Agrícola de Honduras" varias concesiones para establecer empresas de agricultura y obras industriales en el departamento de Colón. La Gaceta \#749-750, 16 marzo de 1891

- Amaya, J. (2000). Los judíos en Honduras. Tegucigalpa: Guaymuras 
- Argueta, M. (1982). Cronología de la Reforma Liberal hondureña. Tegucigalpa: Universitaria

- Bonilla G, A. (28 junio 2001). San Pedro Sula a partir de 1900. Diario Tiempo, San Pedro Sula

- Bureau of the American Republic. (1892). Honduras. Washington, D.C.: Government printing office, bulletin No. 57

- Charles, C. (1890). Honduras the Land of Great Depths. Chicago and New York; Rand, McNally \& Company publishers

- Con los hombres del comercio: teatro Variedades, don José Pérez. (15 enero 1929). Revista Honduras \#21, año I

- Contrata para la canalización de los ríos Ulúa y Blanco. La Gaceta \#167, 14 julio 1882, serie 17

- Contrata relativa a canalizar y hacer navegable el río Chamelecón y traer colonos para que trabajen en sus empresas. La Gaceta \#220, 23 junio 1883, serie 22

- Cruz, M.A. (1989). Don Francisco de Paula Flores, su obra educativa en el departamento de Olancho. Tegucigalpa: Tipografía Nacional

- Decreto No.24 en que se aprueba la concesión otorgada a los señores J.J. Palma y G. Frankel para la fabricación de sacos. La Gaceta \#210, 6 abril 1883, serie 21

- Decreto No.8 en que se aprueba contrato celebrado entre el Gobierno de Honduras y los señores Joseph L. Hance y John J. Waterbury para la construcción del ferrocarril inter oceánico. La Gaceta \#207, 1 abril 1883, serie 21

- Decreto No.9 en que aprueba la concesión otorgada por el Poder Ejecutivo a los señores Joseph L. Hance y John J. Waterbury para fundar un Banco Agrícola Hipotecario. $L a$ Gaceta \#209, 4 abril 1883, serie 21

- Decreto en que se nombra al General don José Antonio Maceo Juez Suplente del Supremo Tribunal de Guerra. La Gaceta \#163, 8 junio 1882, serie 17

- Decreto No. 13 en que se aprueba la contrata celebrada con el General E. A. Lever para canalizar los ríos Ulúa, Blanco y Comayagua. La Gaceta \#477, 9 febrero de 1889, serie 48

- Decreto No. 32 del Poder Legislativo en que se aprueba una concesión otorgada a los Generales Máximo Gómez, José Antonio Maceo y Don Federico Debrot. La Gaceta \#210, 6 abril 1883, serie 21
- Exequátur concedido a la patente en que acredita a don Juan Federico Debrot como cónsul de su majestad británica en los puertos de Omoa y Puerto Caballos o Cortés. La Gaceta \#118, 1 de mayo 1881, serie 12

- Exequátur concedido a la patente en que se nombra a don Carlos Rollof, vicecónsul de Estados Unidos de América en Amapala. La Gaceta \#227, 14 agosto 1883, serie 23

- Franco, J.L. (nov-dic 1954/ene-jun 1955). Antonio Maceo en Honduras en Revista del Archivo y Biblioteca Nacional tomo XXXIII \# 5 al 12

- Memoria presentada por la Secretaría de Estado en los Despachos de Gobernación, Justicia y Fomento al Congreso Nacional. La Gaceta \#212, 20 abril 1883, serie 22

- Moe, A. K. (1904). Honduras: geographical sketch, natural resources, law, economic conditios, actual development, prospect of future growth. Washington: International Bureau of the American Republics. Government printed office

- Rosa, R. (1954). Decreto para fomentar la agricultura. En R.H.V. (comp.) Oro de Honduras, tomo II. Tegucigalpa: Aristón

- Soto, M.A. (1879). Mensaje del presidente de Honduras, contestación del Congreso, I dictamen de la comisión respectiva. Tegucigalpa: Tipografía Nacional

- The American Honduras Company. (1888). Honduras and the Perry Land Grant: a new Field for the farmer, stockman, lumberman, and laborer. Chicago; Donohue \& Henneberry

- Vallejo, A.R. (1891). Primer anuario estadístico correspondiente al año 1889. Tegucigalpa: Tipografía Nacional 